\title{
Understanding the Role of Humanistic Factors in Trade Network Evolution across the Belt and Road Initiative Countries Using the Exponential Random Graph Model
}

\author{
Jianjun $X u \mathbb{D}^{1,2}$ Xiaowei Yang $\mathbb{D}^{3},{ }^{3}$ and Asif Razzaq $\mathbb{D}^{2,4}$ \\ ${ }^{1}$ College of Science \& Technology, Ningbo University, Ningbo 315300, China \\ ${ }^{2}$ School of Economics and Management, Dalian University of Technology, Dalian 116024, China \\ ${ }^{3}$ Business School, Ningbo City College of Vocational Technology, Ningbo 315100, China \\ ${ }^{4}$ Department of Business Administration ILMA University, Karachi 74000, Pakistan \\ Correspondence should be addressed to Jianjun Xu; xujianjun@mail.dlut.edu.cn
}

Received 7 July 2021; Accepted 1 November 2021; Published 30 December 2021

Academic Editor: Anirban Chakraborti

Copyright (c) 2021 Jianjun $\mathrm{Xu}$ et al. This is an open access article distributed under the Creative Commons Attribution License, which permits unrestricted use, distribution, and reproduction in any medium, provided the original work is properly cited.

\begin{abstract}
Humanistic factors have been playing increasingly significant roles in international trade. Recently, the Belt and Road Initiative (BRI) proposed by China has drawn worldwide attention. This paper examines the roles of humanistic factors in international trade networks across the BRI countries. Firstly, we analyzed the structural characteristics of the import trade network across the $61 \mathrm{BRI}$ countries and subsequently adopted the cross-sectional exponential random graph model (ERGM) and temporal ERGM to analyze the role of different humanistic factors in the evolution of import trade network from the static and dynamic perspectives, respectively. The results show the following: (I) the network scale of the import trade across the BRI countries has been expanding, the network density of the trade has been increasing gradually, and the "small-world" characteristics of import network are gradually revealed; (II) all of the factors such as a common (official or spoken) language, a common legal origin, a common religious belief, and ever sibling relationship help the BRI countries establish closer import trade ties; and (III) the differences of trade liberalization and financial liberalization, gross domestic product (GDP), and population in different countries also contribute to the evolution of import trade network among the BRI countries, and the countries with relatively higher GDP and greater population are more active in the import trade network.
\end{abstract}

\section{Introduction}

In the context of economic globalization, culture and economy are regarded as the two most influential forces. The people of different countries have lived in a specific environment for a long time and formed relatively unique humanistic relationships and economic structures. They trade and exchange with each other. Humanistic factors, as the long-term and most profound factors in the production and life of people worldwide, significantly affect trade and investment between countries and enterprises [1]. Based on all kinds of humanistic relationships, various countries across the globe have closely formed an international trade system. A large extent of literature highlights the importance of humanistic factors while studying international trade [1-6].
Many studies about the transaction cost of international trade have shifted from the observable tariff and transportation cost to the indirectly observable transaction cost [6-8]. This study adopts humanistic factors based on indirectly observable transaction cost.

The Belt and Road Initiative (BRI) regions (the "New Silk Road" and the "21st Maritime Silk Road") are the most active areas of global trade and investment. Therefore, this study intends to answer the following complex questions. Do different humanistic factors contribute to closer trade relationships in the BRI regions? Are there significant differences in the role of different humanistic factors in transnational trade along with the BRI regions? The BRI regions, as the world's most-watched regions, have attracted worldwide attention since its beginning. The BRI emphasizes 
cooperation, political mutual trust, economic integration, and cultural inclusion. [9]. The BRI has been growing for more than seven years, from the initial 65 sponsors to 140 countries (up to January 2021) [10]. The bilateral trade volume of 65 sponsor countries within the regions has increased from 4756 billion US dollars in 2013 to 5590 billion US dollars in 2019. With the in-depth implementation of BRI strategy, people to people exchanges and cooperation between these countries continue to deepen, import and export activities become more frequent and active, and their trade relations become more complex. In this case, the traditional linear regression framework is difficult to reveal the evolution characteristic of the complex trade relations effectively, and it is also challenging to explain the evolution mechanism of the international trade relationship across the BRI countries.

With the rise of "the new science of networks," the analytical method of network science is gradually introduced into the study of international trade issues [11-18]. Although these studies have already discussed the typical topological characteristics of the "small-world" nature, scalefree, and high clustering coefficient of the world trade network, there is a lack of discussion on the evolution characteristics of the trade network across the BRI regions, especially lack of discussion on its formation mechanism [19]. Therefore, under the analytical frame of complex networks, this study investigates the role of language, religion, legal system, and so forth in the evolution of trade networks. This study helps all stakeholders to clearly understand the role of different humanistic factors in the transnational trade across the BRI countries and its evolution mechanism.

In recent years, the rapid development of the crosssectional exponential random graph model (ERGM) [20-22] and temporal ERGM, as advanced network analysis tools, has attracted more and more researchers' attention [23-25]. In contrast to traditional econometric models, the cross-sectional ERGM is an effective statistical inference model that analyzes the formation of networks based on the relational data, local network structure, and relational interdependence [21, 22, 25-27]. In addition, the crosssectional ERGM can solve the problem of high-order network structures (such as a star structure, triangle structure, and so on), which cannot be included in the traditional regression model. It is recognized as one of the most effective tools for empirical analysis of network science [28]. More importantly, the temporal ERGM can also effectively solve the temporal dependence problem of longitudinal observation network data [27-29]. Based on the above advantages, both cross-sectional ERGM and temporal ERGM are introduced in this study. We incorporate endogenous network structure variables, exogenous network covariates variables, and individual node attribute variables affecting the evolution of international trade network into a unified framework. This study attempts to prove that the humanistic factors are the driving forces for the development of the international trade network across the BRI regions from the static and dynamic perspectives, respectively. The empirical results show that humanistic factors such as a common (official or spoken) language, a common legal origin, a common religious belief, and ever sibling relationship can help the BRI countries establish closer trade ties.

The contribution of this study is mainly reflected in the following three aspects. Firstly, this paper proposes a superior analytical framework to study the influence of humanistic factors on international trade networks. This paper adopts a complex network analysis paradigm. It puts the pure structure effect of trade network, the social choice effect related to node's attributes, and the relational embeddedness effect of exogenous humanistic factors into a unified analytical framework. The traditional regression model failed to integrate these complexities. Secondly, this paper introduces cross-sectional ERGM and temporal ERGM methods to analyze the influence of different humanistic factors on the trade network evolution from static and dynamic perspectives. To the best of our knowledge, the existing literature only studies the formation of cross-sectional trade networks across the BRI countries, ignoring the influence of the temporal change of trade networks. The temporal ERGM adopted in this paper can analyze the influence of temporal network change and provide strong support for the crosssectional ERGM results. Thirdly, this study confirms the positive role of humanistic factors in the global trade network and the BRI countries, which provides new evidence for people to correctly understand the internal relationship between humanistic factors and international trade.

The rest of the study is organized as follows. In Section 2, we review the related literature. Section 3 presents the model, method, and data. Section 4 elaborates on the empirical results. Section 5 concludes the article and draws policy implications.

\section{Literature Review}

In recent years, more and more attention has been paid to the importance of transaction costs, which cannot be directly observed in international trade, such as language, religious belief, legal origin, and so forth [2-6].

The existing theoretical analysis shows that the research on the influence of humanistic factors on international trade is mainly reflected in the following two aspects. First, humanistic differences lead to differences in goods and services between countries, thus affecting international trade. Scholars who hold this view believe that humanistic factors exist in different goods and services, and humanistic differences determine the trade demand among trading partners, which is one of the fundamental reasons for the emergence and development of international trade and international investment [30]. Second, humanistic factors will have a significant influence on the efficiency of international trade. Scholars who hold this view believe that humanistic factors produce transaction costs by influencing the behavior choices and mutual relations of the participants in international trade, which is an important factor affecting international trade $[1,30]$.

In the empirical analysis, most of the achievements on the importance of humanistic factors in international trade 
are based on the results of econometric analysis of the gravity model [2-6], and there is no consensus on the importance of different humanistic factors in international trade. Felbermayr and Toubal [31], based on the regression results of the gravity model, considered that cultural proximity is an important determinant of bilateral trade volume. Takara [32] used the gravity model to explore the influence of cultural differences on trade decision making, which confirmed that cultural familiarity promoted trade in cultural products. Guo [2] used the trade gravity model and the panel data of China and the United States. His results show that language connection is more important than geographical proximity in foreign trade. Chang et al. [33] studied the role of major trade languages in international trade and foreign direct investment (FDI) flows, and the results showed that a common language increases the flow of trade and FDI. Melitz [34] and Melitz and Toubal [35] also confirmed the positive influence of a common language on bilateral trade flows. Fidrmuc and Fidrmuc [36] not only found that broad language knowledge is an important determinant of foreign trade but also believed that English plays a significant role. Lewer and Van den Berg [37] found that three of the eight religious cultures in the world directly stimulated international trade by using the panel gravity model of 84 countries from 1995 to 2000. Most religious cultures seem to increase trade through influence on other social institutions, and six of eight religions have a network effect of growing trade.

Another strand of literature argued that humanistic factors are not conducive to international trade. Based on the data of 67 countries, Tadesse and White [4] conducted an empirical analysis and found that the cultural differences between countries have a significant and sustained negative influence on the total and classified trade flows. Liu et al. [6] showed that the transaction costs related to cultural distance and institutional distance inhibit the bilateral trade flows between China and the BRI countries. According to Lankhuizen and de Groot [38], the relationship between international trade and cultural differences is nonlinear. International trade decreases with the increase of cultural distance when the cultural differences between the two countries exceed a certain threshold. Guo [2] employed the panel trade gravity model between China and the United States to prove that religious similarity and cultural similarity have a negligible relationship in the overall foreign trade between the United States and China. However, religious differences often hinder foreign trade with poor countries and regions.

In addition, relational data are also discussed. For example, Chong et al. [39] used the quadratic assignment problem (QAP) model to verify the spatial effects of spatial proximity, cultural differences, and trade agreements on the international trade network along with the BRI countries. Xu and Cheng [1] constructed the QAP two-part weighted network and confirmed the role of a common language, common religious belief, and regional trade agreements in promoting the impact of international trade in services. But this kind of achievement is very scarce.

To sum up, it is rare to discuss the importance of humanistic factors in international trade under the network analysis paradigm. This paper introduces the ERGM under a unified network analysis framework and considers the influence of language, religious belief, legal origin, and other factors on import trade, which undoubtedly helps to enrich and improve the research in this field.

\section{Research Design}

3.1. Representation of Relational Network. According to Dong et al. [40], suppose a trade network $G=(V, E)$ contains the nodes $V$ and edges $E$, where $V=\left\{v_{i}: 1,2, \ldots, n\right\}$, and $n$ is the number of nodes; $E=\left\{e_{i}: 1,2, \ldots, m\right\}$, and $m$ is the number of edges; in this model, the nodes are the nations, the edges are considered the import trade relationship between two countries across the BRI regions, and the import value $w_{i j}$ from country $i$ to country $j$ is considered as the weight.

\subsection{Method of Describing Network Structure Characteristics}

(1) Average Degree. The degree is the number of edges directly connected to the node, while the average degree is the average of all nodes in the network. The higher the average degree, the more the number of connections between nodes; otherwise, it indicates fewer connections between nodes. The formula for the average degree is as follows [41]:

$$
\bar{K}=\frac{1}{N} \sum_{i}^{N} K_{i}
$$

where $\bar{K}$ is the average degree of the network, $N$ is the number of nodes, and $K_{i}$ is the degree value of node $i$.

(2) Weighted Average Degree. The weighted degree is based on the node degree, which takes the edge weight into account. The weighted average degree is the average value of all nodes' degree in the network. The higher the weighted average degree, the higher the strength of the connection between nodes; otherwise, it indicates that the connection strength of nodes is low. The calculation formula is as follows:

$$
\bar{S}=\frac{1}{N} \sum_{i}^{N} w_{i j}
$$

where $\bar{S}$ is the weighted average degree of the network, $N$ is the number of nodes, and $w_{i j}$ is the weight of the connection between nodes $i$ and $j$.

(3) Network Density. Network density represents the number and complexity of network relationships. The more the number of network relationships, the greater the network density, which means that the network has a greater influence on the attribute (attitude, behavior, etc.) of nodes. The specific calculation is as follows:

$$
D=\frac{M}{[N(N-1)},
$$


where $D$ is the network density, $M$ represents the actual number of relationships, $N$ is the number of network nodes, and $N(N-1)$ is the maximum number of relationships in the directed network diagram.

(4) Average Clustering Coefficient. The clustering coefficient is the ratio of the actual number of nodes connected to each other and the maximum number of connected edges theoretically realized between these nodes. The average clustering coefficient is the average value of the clustering coefficient of all nodes in the network, which reflects the degree of clustering among nodes in the network. The calculation formula of the average clustering coefficient of a directed network is as follows [42]:

$$
C=\frac{1}{N} \sum_{i}^{N} \frac{n_{i}}{k_{i}\left(k_{i}-1\right)}
$$

where $C$ is the average clustering coefficient of the network, $N$ is the number of nodes, $k_{i}$ is the number of adjacent nodes of node $i$, and $n_{i}$ is the number of actually connected edges between adjacent nodes of node $i$.

(5) Average Path Length. The average path length is the average of the shortest path distance between any two nodes in the network, which describes the global efficiency of the network and the convenience of the connection between nodes. The average path length of the directed network is calculated as follows [43]:

$$
L=\frac{1}{N(N-1)} \sum_{j}^{N} d_{i j}
$$

where $L$ is the average path length, $N$ is the number of nodes, and $d_{i j}$ is the shortest path distance between nodes $i$ and $j$.

\subsection{The Cross-Sectional ERGM and Temporal ERGM of Import Network}

3.3.1. Specification of ERGM. Suppose weighted trade network matrices can be expressed as $y=\left[y_{i j}\right]$. Therefore, $\operatorname{Pr}(Y=y \mid \theta]$ can be used to represent the probability of $y$ appearing in the possible set $Y$ under the condition $\theta$. According to Liu et al. [44] and Robins et al. [45], assuming that the probability of observed international trade network $(y)$ depends on different kinds of network structure statistics, the general form of the cross-sectional ERGM model can be expressed as follows:

$$
\operatorname{Pr}(Y=y \mid \theta) \equiv P_{\theta}(y)=\frac{1}{\kappa} \exp \left\{\theta^{T} z(y)+\theta_{a}^{T} z_{a}(y, x)+\theta_{b}^{T} z_{b}(y, g)\right\},
$$

where $\kappa$ denotes constant, which is mainly used to ensure that the model has an appropriate probability distribution; $z(y)$ represents a series of endogenous network structure variables that may affect the evolution of the international trade network; $z_{a}(y, x)$ refers to a series of exogenous network covariates that affect the structure of the international trade network; and $z_{b}(y, g)$ represents a series of node attribute variables that affect the structure of the international trade network. $\theta, \theta_{a}$, and $\theta_{b}$ represent the estimation parameter vectors of pure network structure variables, exogenous network covariates, and node attribute variables, respectively. If these estimated parameters can meet the test of statistical significance, it shows that the variables have an important influence on the evolution of an international trade network.

Furthermore, to discuss the dynamic evolution mechanism of trade network structure in different periods, referring to the practice of Hanneke et al. [29] and Wu et al. [27], the temporal dependence of the observed network is considered. The observation networks in lagged $t-1$ period $\left(y^{t-1}\right)$ to $t-k$ period $\left(y^{t-k}\right)$ are introduced into model (6). The following temporal ERGM was constructed for analysis.

$$
\operatorname{Pr}\left(Y=y^{t} \mid y^{t-1}, \ldots, y^{t-k}, \theta\right)=\frac{1}{\kappa} \exp \left\{\theta^{T} z\left(y^{t}, y^{t-1}, \ldots, y^{t-k}\right)+\theta_{a}^{T} z_{a}\left(y^{t}, y^{t-1}, \ldots, y^{t-k}\right)\left|X_{t}+\theta_{b}^{T} z_{b}\left(y^{t}, y^{t-1}, \ldots, y^{t-k}\right)\right| G_{t}\right\}
$$

where $\kappa$ denotes a constant, which is mainly used to ensure that the model has an appropriate probability distribution; $z\left(y^{t}, y^{t-k}, \ldots, y^{t-1}\right)$ represents a series of endogenous network structure variables that may affect the evolution of the international trade network; $z_{a}\left(y^{t}, y^{t-1}, \ldots, y^{t-k} \mid X_{t}\right)$ refers to a series of exogenous network covariates that affect the evolution of the international trade network; and $z_{b}\left(y^{t}, y^{t-1}, \ldots, y^{t-k} \mid G_{t}\right)$ represents a series of node attribute variables that affect the evolution of the international trade network. $\theta, \theta_{a}$, and $\theta_{b}$ represent the estimation parameter vectors of pure network structure variables, exogenous network covariates, and node attribute variables, respectively. If these estimated parameters can meet the test of statistical significance, it shows that the variables have an important influence on the evolution of an international trade network.

3.3.2. Variables in the ERGM. When packages named ERGM [26, 46], Statnet [47], and Btergm [29] in R are used to fit the parameters of the cross-sectional ERGM and temporal ERGM, 118 kinds of network structure statistics can be selected [48, 49]. According to the need for research and repeated debugging, the pure structural endogenous variables, network covariates, and attribute variables are shown in Table 1.

(I) Endogenous Network Structure Variables in the ERGM. 
Endogenous network structure variables are mainly used to test and control the endogenous self-organization characteristics (i.e., a pure network effect). In this study, two endogenous network structure variables named edges and mutual are selected to enter the model. If the network structure statistics in the ERGM only consider the edge number as the explanatory variable, the ERGM is also called the Bernoulli model. If the ERGM only considers edges and mutual statistics, then this model is considered as the simplest form of dyadic independence model, also known as reciprocal $p^{*}$ model.

\section{(II) Exogenous Network Covariates in the ERGM.}

Network covariate statistics mainly test the explanatory power and promoting effect of external network relations on the formation of trade networks. This study takes into account the role of five humanistic relations networks, including the common official language network (Netc(lang_off)), the common spoken language network (Netc(lang_theno)), the common legal origin network (Netc(comleg)), the common religious belief network (Netc(comrelig)), and ever sibling relationship (Netc(sibling_ever)). According to $\mathrm{Xu}$ and Cheng [1] and $\mathrm{Wu}$ et al. [28], we employ an adjacency unweighted matrix to denote the different humanistic relationships.

(III) Exogenous Node Attributes Variables in the ERGM.

Node attribute variables can be used to investigate the main effect, difference effect, homogeneity effect, sender effect, and receiver effect of the node attributes. Among them, the main effects are mainly used to measure the influence of the aggregation continuous attribute characteristics of the nodes on the formation of network relations. This paper focuses on the influence of trade liberalization (Main(tradefree)), investment liberalization (Main(invfree)), and financial liberalization (Main (finfree)) on the evolution of an international trade network.

Absolute difference effects are mainly used to measure the difference of continuous attribute values corresponding to different node pairs, which have an influence on the evolution of network relationships. This paper focuses on the influence of different economic scales (Diff(gdp)), population difference (Diff(pop)), and the different cost of business start-up procedures (Diff(entry_cost)) on the evolution of an international trade network.

Homophily effect is mainly used to measure whether homogeneity of the different nodes will affect the formation of network relationships or not. In this paper, we rank them according to economic scale (gdp) and population size (pop), take one-third of the samples into three categories: high, middle, and low, and investigate whether the BRI countries with similar attributes tend to import between groups.

Sender effects measure the degree to which actors with a particular attribute send more relationships than other actors. Receiver effects measure the degree to which actors with particular attributes tend to receive relationships. This paper mainly considers the sender effect and receiver effect of the attribute variables of economic scale (gdp) and population size (pop) of the sample countries, respectively.

\subsection{Parameter Simulation and Diagnostic Method of the} ERGM. There are two kinds of methods to fit the parameters of the cross-sectional ERGM. One is the maximum pseudolikelihood estimation (MPLE). The disadvantage of this method is that it violates the dependency assumption between relational data variables, resulting in biased estimation results [49]. Another is Markov Monte Carlo maximum likelihood estimation (MCMC MLE). One of the characteristics of MCMC MLE is that the estimated parameters tend to be stable through continuous simulation and parameter modification. MCMC MLE is chosen to estimate the parameters of the cross-sectional ERGM in this study.

Parameter estimation methods of the temporal ERGM model mainly include MCMC MLE and bootstrapped pseudo-likelihood. This paper chooses the former method for the empirical test and the latter method for the robust test.

In addition, the fittest and parsimonious ERGM can be selected by the Akaike information criterion (AIC) and Bayesian information criterion (BIC) [50], in which $\mathrm{AIC}=2 k-2 \ln (L), \mathrm{BIC}=\ln (n) \times k-2 \ln (L), L$ is the $\log -$ likelihood value of the model, $n$ is the sample size, and $K$ is the number of variables in the ERGM. AIC and BIC consider the simplicity and accuracy of the ERGM and avoid the overfitting problem caused by too many explanatory variables contained in the ERGM [22]. The goodness of fit (GOF) is used to evaluate the fitting effect of the model.

3.5. Data Sources. Sample details of 61 BRI countries are shown in Appendix (see Supplementary Materials). Import trade data of sample countries come from UN Comtrade_SITC dataset. Common official or primary language data, a common language spoken by at least $9 \%$ of the population data, common religious belief data, common legal origin data, ever sibling relationship data, and entry cost data come from the CEPII Gravity Database [51]. The basic data of GDP and population are all from the World Bank Database. The measurement data of trade liberalization, investment liberalization, and financial liberalization come from the database provided by the Global Heritage Fund.

\section{Empirical Results and Explanation}

4.1. Structural Characteristics of Import Trade Network. The statistical indicators of the overall network characteristics of import trade network from 2001 to 2019 years are shown in Table 2 . The results of Table 2 show that the import trade network of BRI countries has three characteristics as follows:

(1) The network scale of import trade is expanding.

From the perspective of the number of edges, the edges of the BRI countries increased from 2196 in 2001 to 3011 in 2019, and the average annual growth 
TABLE 1: Endogenous and exogenous network structure variables of directed network in the ERGM.

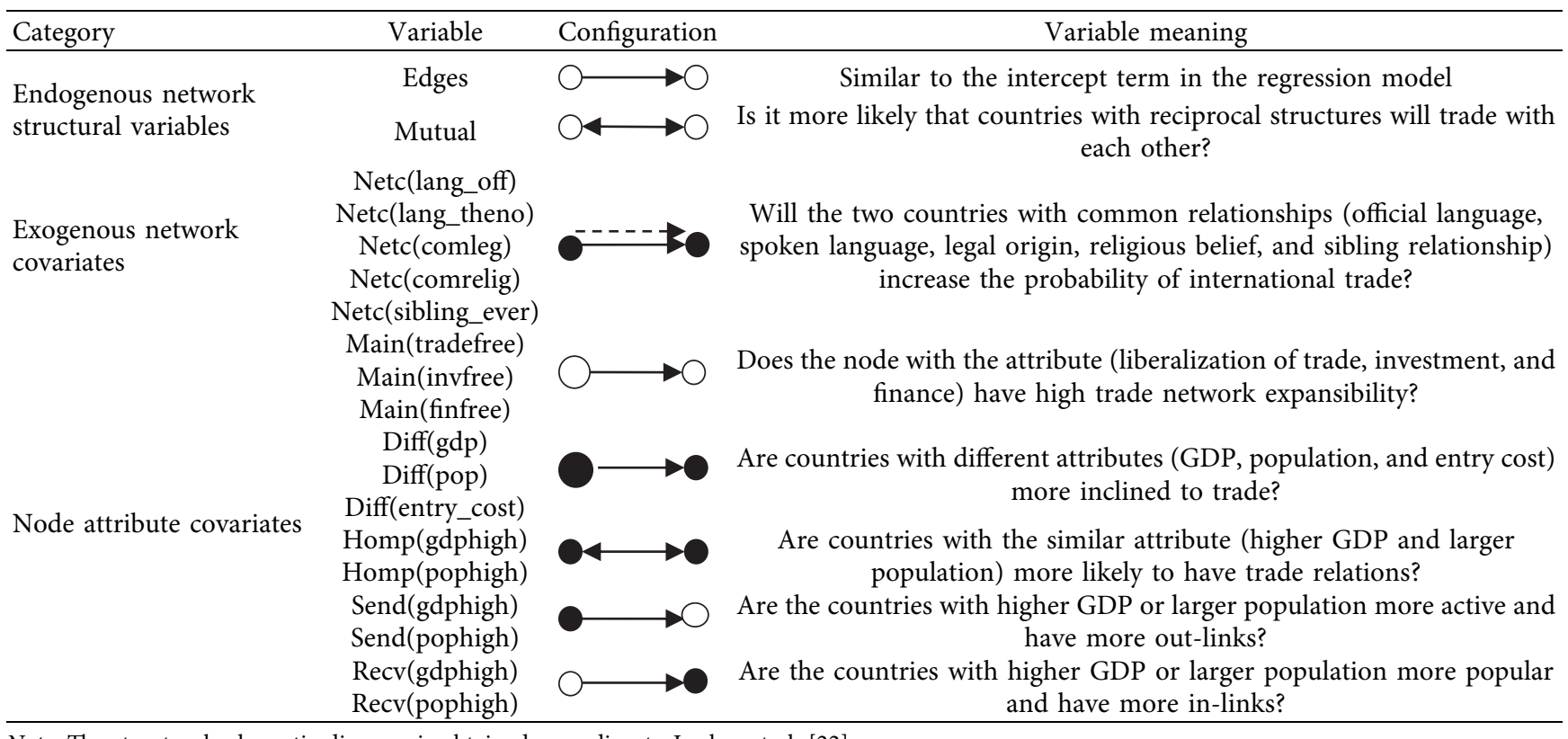

Note. The structural schematic diagram is obtained according to Lusher et al. [22].

TABLE 2: The overall characteristics of the international trade network across the BRI countries.

\begin{tabular}{ccccccc}
\hline Year & Edges & Average degree & Weighted average degree & Network density & Average clustering coefficient & Average path length \\
\hline 2001 & 2196 & 72.000 & 5208419 & 0.600 & 0.738 & 1.347 \\
2002 & 2262 & 74.164 & 5947097 & 0.618 & 0.739 & 1.326 \\
2003 & 2429 & 79.639 & 7633007 & 0.664 & 0.766 & 1.308 \\
2004 & 2477 & 81.213 & 10259844 & 0.677 & 0.769 & 1.307 \\
2005 & 2537 & 83.180 & 13086754 & 0.693 & 0.782 & 1.279 \\
2006 & 2571 & 84.295 & 16033802 & 0.702 & 0.804 & 1.276 \\
2007 & 2649 & 86.852 & 20563190 & 0.724 & 0.803 & 1.273 \\
2008 & 2648 & 86.820 & 26633020 & 0.723 & 0.796 & 1.254 \\
2009 & 2624 & 86.033 & 20449284 & 0.717 & 0.819 & 1.263 \\
2010 & 2812 & 92.197 & 26178402 & 0.768 & 0.805 & 1.219 \\
2011 & 2748 & 90.098 & 33058908 & 0.751 & 0.823 & 1.225 \\
2012 & 2818 & 92.393 & 35845757 & 0.770 & 0.829 & 1.213 \\
2013 & 2838 & 93.049 & 37434188 & 0.775 & 0.823 & 1.220 \\
2014 & 2812 & 92.197 & 38056127 & 0.768 & 0.836 & 1.204 \\
2015 & 2867 & 94.000 & 33533847 & 0.783 & 0.811 & 1.198 \\
2016 & 2751 & 90.197 & 31485917 & 0.752 & 0.829 & 1.205 \\
2017 & 2840 & 93.115 & 37327285 & 0.776 & 0.871 & \\
2018 & 2765 & 90.656 & 41480002 & 0.823 & & 1.171 \\
2019 & 3011 & 98.721 & 45155808 & & & \\
\hline
\end{tabular}

rate is $1.82 \%$, which indicates that the import trade partnership of the BRI countries is more closer. The average degree has increased from 72 in 2001 to 98.721 in 2019, with an average annual growth rate of $1.82 \%$; the average weighted degree has risen from 5208418 of 2001 to 45155808 in 2019 , with an annual growth rate of $13.94 \%$, which is faster than the growth rate of the edges.

(2) The network density of import trade is gradually increasing.

Network density is one of the important indicators to describe the overall attribute characteristics of the network. The network density has increased from
0.600 in 2001 to 0.823 in 2019, with an average annual increasing rate of $1.83 \%$.

(3) The "small-world" characteristics of import network are gradually revealed.

Average clustering coefficient and average path length are two main indexes to measure small-world characteristics $[43,52]$. If a network has a shorter average path length and higher average clustering coefficient than a random network of a similar scale, it indicates that the network has small-world characteristics. The results in Table 2 report that the average clustering coefficient of the BRI countries increases from 0.738 in 2001 to 0.871 in 2019; 
meanwhile, the average path length is shortened from 1.347 in 2001 to 1.1171 in 2019, which gradually reflects the characteristics of a small-world network.

In order to directly inspect the characteristics of import trade network across the BRI countries, we use Gephi 0.9.1 to draw the import trade network graph of the 61 BRI countries in 2001, 2005, 2013, and 2019, as shown in Figure 1, respectively. The connection between the two countries indicates that there is an import relationship between them. The thickness of the connection line is directly proportional to the weighted degree of the import trade network. The larger the trade volume between the two countries, the thicker the connection. The size of the node is directly proportional to the centrality of a country's import trade network. The larger the node, the higher the core status of the country's import trade network. It can be seen from Figure 1 that in 2001 and 2005, Singapore, China, Malaysia, and Russia were the countries at the centre of the import trade network. As time went on, only China fell at the core of the import trade network in 2013 and 2019. This is consistent with the conclusion of Chen and Qiang [19] and Song et al. [53].

\subsection{Static Analysis Based on the Cross-Sectional ERGM}

4.2.1. Analysis of the Import Trade Network in a Specific Year. In order to reveal the influence of the humanistic factors on the import trade network, we fitted the coefficient of model (6) based on the MCMC MLE method and chose the best cross-sectional ERGM by AIC and BIC. M(1) in Table 3 examined the influence of the common official language (NETC(langoff)) on the import trade network in 2019 based on the reciprocal $p^{*}$ model. Furthermore, we consider the influence of node attributes of sample countries based on M(1). The statistics of AIC (2261.1183) and BIC (2354.1965) of $\mathrm{M}(2)$ are significantly lower than the corresponding AIC (2961.5634) and BIC (2980.1791) in M(1), which indicates that the estimation result of $\mathrm{M}(2)$ is better than $\mathrm{M}(1)$. Using a similar strategy, based on cross-sectional data of different years, this paper investigated the effect of the common official language (Netc(lang_off)), the common spoken language (Netc(lang_ethno)), the common religion(Netc(comrelig)), the common legal origin (Netc(comleg)), and ever sibling relationship (Netc(sibling_ever)) on the import trade network with the node attributes. The fitting results of model (6) are given in Table 3.

Firstly, from the perspective of endogenous network structure variables, the estimated parameters of edges in $\mathrm{M}(2)-\mathrm{M}(6)$ are all significantly negative, which confirms that the relationship between import networks is not formed randomly. Therefore, it is meaningful to further analyze the influencing factors of the formation of various network relationships; the estimation coefficient of mutual in $\mathrm{M}(1)-\mathrm{M}(6)$ is significantly positive, which indicates that the import trade between the BRI countries is mutual. This is consistent with the conclusion of $\mathrm{Xu}$ et al. [54].

Secondly, from the perspective of exogenous network covariates, the results of parameter estimation of the five humanistic relationships network covariates in $\mathrm{M}(2)-\mathrm{M}(6)$ have passed the statistical significance test, and the estimated parameters of Netc(lang_off), Netc(lang_ethno), Netc(comleg), Netc(comrelig), and Netc(sibling_ever) are significantly positive, which shows that a common official language, a common spoken language relationship, a common legal system origin, common religious beliefs, and ever sibling relationship will help the 61 BRI countries establish closer trade ties in 2019. Among them, the coefficient of the official language and the coefficient of the spoken language are consistent with the conclusion of $\mathrm{Wu}$ et al. [27].

Finally, we analyze the effects of individual attribute covariates.

(I) In terms of the main effect, the estimated coefficients of Main(tradefree) and Main(finfree) in $\mathrm{M}(2)-\mathrm{M}(6)$ are significantly positive, respectively, which shows that trade liberalization and financial liberalization have a significant role in promoting the formation of import trade networks of sample countries, which is consistent with the conclusion of Xu et al. [54]. The estimated coefficients of Main(invfree) in $\mathrm{M}(2)-\mathrm{M}(6)$ are negative, while those only in $\mathrm{M}(6)$ are significant. Therefore, whether investment liberalization hinders the formation of the import trade relationship needs to be further verified.

(II) In the absolute difference effect, the estimated coefficients of Diff(gdp) and Diff (pop) in $\mathrm{M}(2)-\mathrm{M}(6)$ are significantly positive, which indicates that the differences in GDP and population size are conducive to the establishment of bilateral import trade relations of the BRI countries in 2019. The estimated coefficient of Diff(entry_cost) is insignificantly negative, so its role needs to be further verified.

(III) In the aspect of homophily effect, the estimated coefficients of Homp(gdphigh) and Homp(pophigh) in $\mathrm{M}(2)-\mathrm{M}(6)$ are significantly positive, which indicates that among BRI countries in 2019, the import propensity among large GDP countries is large, as well as the import propensity of lager population countries.

(IV) In the aspect of sender effect, Send(gdphigh) and Send(pophigh) are both significantly positive in $\mathrm{M}(2)-$ $\mathrm{M}(6)$, which indicates that big GDP countries and large population countries are more popular in export and import.

(V) In terms of receiver effect, Recv(gdplow) and Recv(poplow) are both significantly positive in $M(2)-$ $\mathrm{M}(6)$, which indicates that the countries with big GDP and large population are more active in import trade and have more in-links.

4.2.2. Comparatively Static Analysis of Import Trade Network in Different Years. To further investigate the effects of the differences of humanistic relationships on the import trade network in different periods, we fit the coefficients of model (6) using data of years 2001, 2005, and 2015. Figure 2 shows the influence coefficient of five humanistic relationships variables on the import trade network from 2001 to 2019. It can be seen from Figure 2 that the influencing coefficients of these five humanistic relationships variables on import trade 

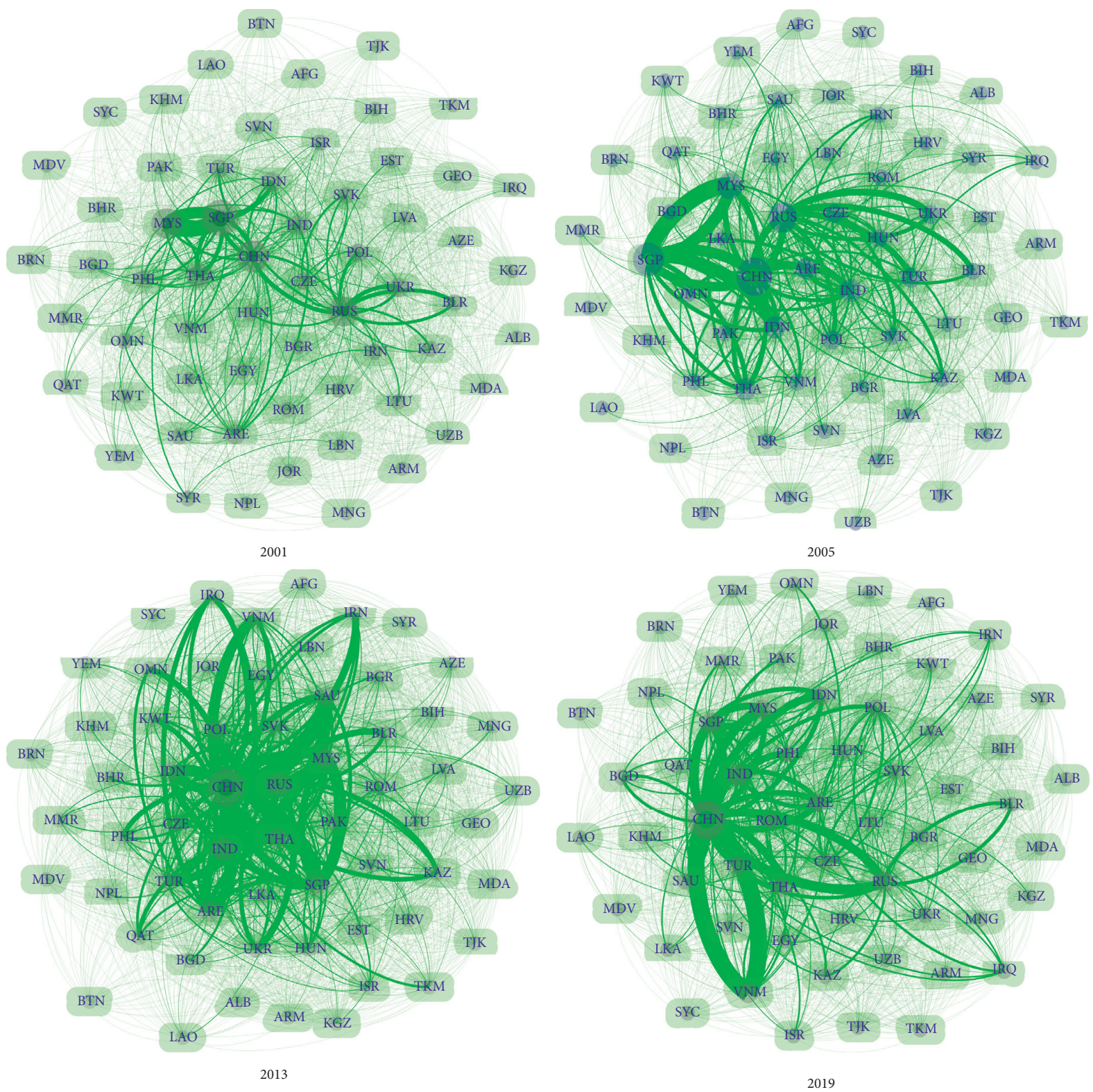

FIGURE 1: Evolution of import trade network of the BRI countries.

networks are all significantly positive in 2001, 2005, 2013, and 2019, which shows that a common official language, a commonly spoken language, a common religious belief, a common legal origin, and ever sibling relationship help 61 BRI countries establish closer import trade ties. On the whole, the effects of Netc(lang_off) and Netc(sibling_ever) are relatively bigger; however, the impact of Netc(comleg) on the import trade network is relatively small, and the effects of Netc(lang_ethno) and Netc(comrelig) on import trade network are relatively moderate.

\subsection{Dynamic Analysis Based on the Temporal ERGM}

4.3.1. The Estimated Results of the Temporal ERGM by Markov Monte Carlo Maximum Likelihood Estimation. To further reveal the dynamic effect of the humanistic relationship on import trade network in the BRI countries, we further constructed the temporal ERGM with a collection of the network datasets of 2001, 2005, 2013, and 2019 and fit the coefficient by Markov Monte Carlo maximum likelihood estimation (MCMC MLE). The result is presented in Table 4 . We further calculate the fitting coefficients of model (7). Figure 3 shows the GOF fitting effect of $M(7)$ as an example. In Figure 3, the solid black line represents the statistical characteristics of the observation network, and the box line represents the statistical characteristics of the simulation network. Generally speaking, if the median of the boxplot is close to the solid black line of the observation network, the fitting of the model is better. Figure 3 shows that the fitting effect of $\mathrm{M}(7)$ is better. The GOF fitting effects of $\mathrm{M}(8)-\mathrm{M}(11)$ are very similar, which shows that the fitting effects of $\mathrm{M}(8)-\mathrm{M}(11)$ are also good. The meaning of each estimated parameter is further explained below. 
TABLE 3: The estimated results of the cross-sectional ERGM (2019).

\begin{tabular}{|c|c|c|c|c|c|c|}
\hline & $\mathrm{M}(1)$ & $\mathrm{M}(2)$ & $\mathrm{M}(3)$ & $\mathrm{M}(4)$ & $\mathrm{M}(5)$ & $\mathrm{M}(6)$ \\
\hline Edges & $\begin{array}{c}-2.9976^{* * *} \\
(0.0911)\end{array}$ & $\begin{array}{c}-9.7759^{* * *} \\
(0.0518)\end{array}$ & $\begin{array}{c}-9.8578^{* * *} \\
(0.0487)\end{array}$ & $\begin{array}{c}-9.8726^{* * *} \\
(0.0499)\end{array}$ & $\begin{array}{c}-11.5684^{* * *} \\
(0.0531)\end{array}$ & $\begin{array}{c}-10.4221^{* * *} \\
(0.0497)\end{array}$ \\
\hline Mutual & $\begin{array}{c}4.7130^{* * * *} \\
(0.1856)\end{array}$ & $\begin{array}{c}3.9987^{* * *} \\
(0.0305)\end{array}$ & $\begin{array}{c}4.0140^{* * *} \\
(0.0165)\end{array}$ & $\begin{array}{c}4.0022^{* * *} \\
(0.1905)\end{array}$ & $\begin{array}{c}3.9846^{* * *} \\
(0.0289)\end{array}$ & $\begin{array}{c}3.9773^{* * *} \\
(0.1936)\end{array}$ \\
\hline Main(tradefree) & & $\begin{array}{c}0.0353^{* * *} \\
(0.0016)\end{array}$ & $\begin{array}{c}0.0361^{* * *} \\
(0.0016)\end{array}$ & $\begin{array}{c}0.0341^{* * *} \\
(0.0018)\end{array}$ & $\begin{array}{c}0.0465^{* * *} \\
(0.0018)\end{array}$ & $\begin{array}{c}0.0394^{* * *} \\
(0.0017)\end{array}$ \\
\hline Main(invfree) & & $\begin{array}{l}-0.0016 \\
(0.0027)\end{array}$ & $\begin{array}{l}-0.0030 \\
(0.0027)\end{array}$ & $\begin{array}{l}-0.0022 \\
(0.0029)\end{array}$ & $\begin{array}{l}-0.0018 \\
(0.0028)\end{array}$ & $\begin{array}{c}-0.0061^{* *} \\
(0.0030)\end{array}$ \\
\hline Maim(finfree) & & $\begin{array}{c}0.0037 \\
(0.0033)\end{array}$ & $\begin{array}{c}0.0047 \\
(0.0031)\end{array}$ & $\begin{array}{c}0.0056 \\
(0.0035)\end{array}$ & $\begin{array}{c}0.0026 \\
(0.0034)\end{array}$ & $\begin{array}{l}0.0073^{* *} \\
(0.0034)\end{array}$ \\
\hline Diff(popd) & & $\begin{array}{l}0.0003^{*} \\
(0.0002)\end{array}$ & $\begin{array}{c}0.0003 \\
(0.0002)\end{array}$ & $\begin{array}{l}0.0004^{* *} \\
(0.0002)\end{array}$ & $\begin{array}{c}0.0005^{* * *} \\
(0.0002)\end{array}$ & $\begin{array}{c}0.0002 \\
(0.0002)\end{array}$ \\
\hline Diff(gdpd) & & $\begin{array}{c}0.0002^{* * *} \\
(0.0000)\end{array}$ & $\begin{array}{c}0.0002^{* * *} \\
(0.0000)\end{array}$ & $\begin{array}{c}0.0002^{* * *} \\
(0.0000)\end{array}$ & $\begin{array}{c}0.0002^{* * *} \\
(0.0000)\end{array}$ & $\begin{array}{c}0.0002^{* * *} \\
(0.0000)\end{array}$ \\
\hline Diff(entry_cost) & & $\begin{array}{l}-0.0047 \\
(0.0041)\end{array}$ & $\begin{array}{l}-0.0043 \\
(0.0039)\end{array}$ & $\begin{array}{l}-0.0020 \\
(0.0036)\end{array}$ & $\begin{array}{l}-0.0030 \\
(0.0041)\end{array}$ & $\begin{array}{l}-0.0023 \\
(0.0037)\end{array}$ \\
\hline Homo(gdphigh) & & $\begin{array}{c}0.1179 \\
(0.0817)\end{array}$ & $\begin{array}{l}0.1502^{*} \\
(0.0839)\end{array}$ & $\begin{array}{c}0.1166 \\
(0.0789)\end{array}$ & $\begin{array}{l}0.1416^{*} \\
(0.0850)\end{array}$ & $\begin{array}{c}0.0980 \\
(0.0819)\end{array}$ \\
\hline Homo(pophigh) & & $\begin{array}{l}0.1746^{* *} \\
(0.0869)\end{array}$ & $\begin{array}{l}0.1515^{*} \\
(0.0814)\end{array}$ & $\begin{array}{l}0.1541^{*} \\
(0.0854)\end{array}$ & $\begin{array}{l}0.1613^{*} \\
(0.0823)\end{array}$ & $\begin{array}{l}0.1515^{*} \\
(0.0845)\end{array}$ \\
\hline Send(gdphigh) & & $\begin{array}{c}0.5787^{* * *} \\
(0.1080)\end{array}$ & $\begin{array}{c}0.5378^{* * *} \\
(0.0997)\end{array}$ & $\begin{array}{c}0.6030^{* * *} \\
(0.1091)\end{array}$ & $\begin{array}{c}0.6165^{* * *} \\
(0.1069)\end{array}$ & $\begin{array}{c}0.6321^{* * *} \\
(0.1001)\end{array}$ \\
\hline Send(pophigh) & & $\begin{array}{c}0.6110^{* * *} \\
(0.0937)\end{array}$ & $\begin{array}{c}0.6473^{* * *} \\
(0.0967)\end{array}$ & $\begin{array}{c}0.5883^{* * * *} \\
(0.0980)\end{array}$ & $\begin{array}{c}0.5880^{* * * *} \\
(0.0989)\end{array}$ & $\begin{array}{c}0.6442^{* * *} \\
(0.1006)\end{array}$ \\
\hline $\operatorname{Recv}$ (gdphigh) & & $\begin{array}{c}0.9457^{* * *} \\
(0.1073)\end{array}$ & $\begin{array}{c}0.9050^{* * *} \\
(0.1025)\end{array}$ & $\begin{array}{c}0.9837^{* * *} \\
(0.1018)\end{array}$ & $\begin{array}{c}0.9649^{* * *} \\
(0.1067)\end{array}$ & $\begin{array}{c}0.9990^{* * *} \\
(0.1024)\end{array}$ \\
\hline Recv(pophigh) & & $\begin{array}{c}0.4949^{* * *} \\
(0.0968)\end{array}$ & $\begin{array}{c}0.5120^{* * *} \\
(0.0969)\end{array}$ & $\begin{array}{c}0.4345^{* * *} \\
(0.1007)\end{array}$ & $\begin{array}{c}0.4677^{* * *} \\
(0.0998)\end{array}$ & $\begin{array}{c}0.4889^{* * * *} \\
(0.0990)\end{array}$ \\
\hline Netc(comlang_off) & $\begin{array}{c}0.6127^{* * *} \\
(0.1129)\end{array}$ & $\begin{array}{c}1.0474^{* * *} \\
(0.1347)\end{array}$ & & & & \\
\hline Netc(comlang_ethno) & & & $\begin{array}{c}0.7464^{* * *} \\
(0.1172)\end{array}$ & & & \\
\hline Netc(comleg) & & & & $\begin{array}{c}0.5236^{* * *} \\
(0.0770)\end{array}$ & & \\
\hline Netc(comrelig) & & & & & $\begin{array}{c}1.0175^{* * *} \\
(0.1212)\end{array}$ & \\
\hline Netc(sibling_ever) & & & & & & $\begin{array}{c}0.7326^{* * *} \\
(0.0889)\end{array}$ \\
\hline AIC & 2961.5634 & 2261.1183 & 2278.3272 & 2268.6251 & 2253.0626 & 2257.5920 \\
\hline $\mathrm{BIC}$ & 2980.1791 & 2354.1965 & 2371.4055 & 2361.7034 & 2346.1409 & 2350.6703 \\
\hline
\end{tabular}

Note. $^{* * *} p<0.01 ;{ }^{* *} p<0.05 ;{ }^{*} p<0.1$; the values in parentheses are standard errors.

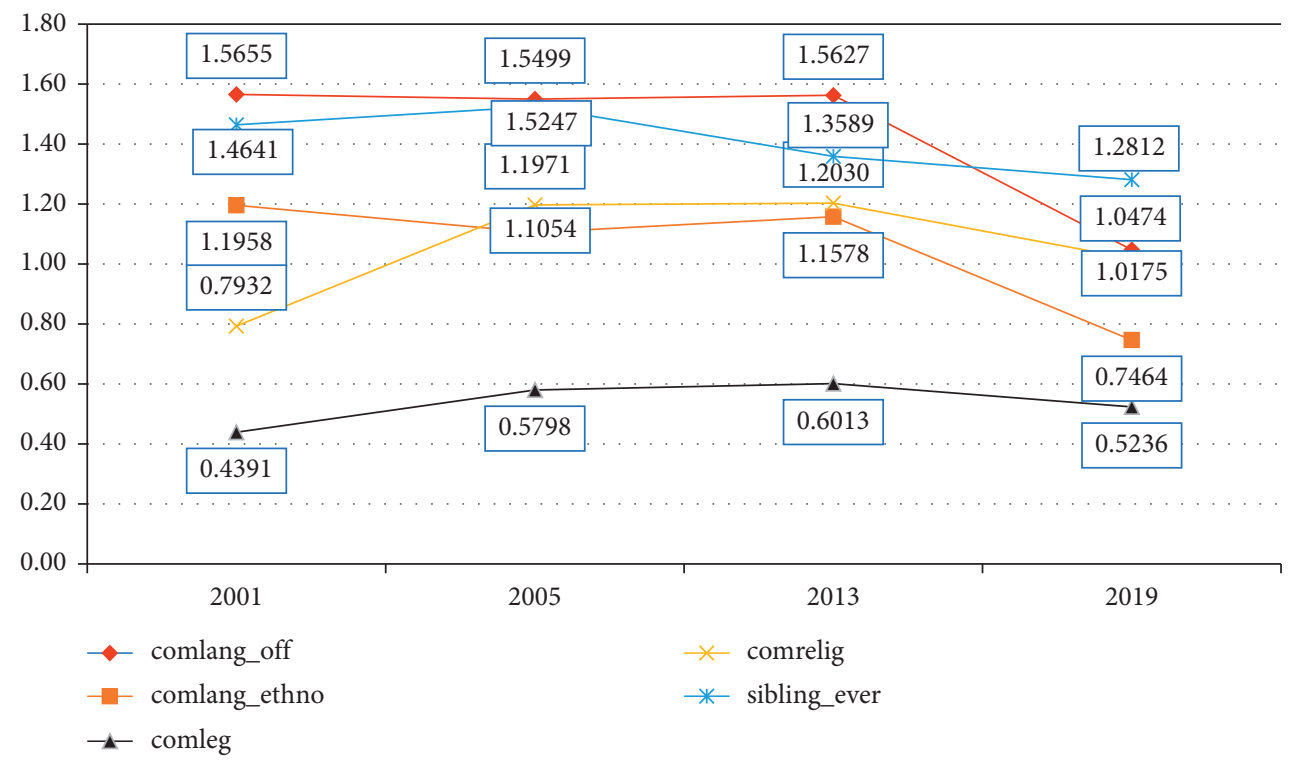

FIgURE 2: The role of the humanistic factors in the import trade network in different years. 
TABLE 4: The estimated results of the temporal ERGM by MCMC MLE.

\begin{tabular}{|c|c|c|c|c|c|}
\hline & $\mathrm{M}(7)$ & $\mathrm{M}(8)$ & $\mathrm{M}(9)$ & $\mathrm{M}(10)$ & $\mathrm{M}(11)$ \\
\hline Edges & $-3.3927^{* * *}(0.0164)$ & $-3.4223^{* * *}(0.0161)$ & $-3.5163^{* * *}(0.0154)$ & $-3.3588^{* * *}(0.0159)$ & $-3.2989^{* * *}(0.0157)$ \\
\hline Mutual & $2.5622^{* * *}(0.0065)$ & $2.5394^{* * *}(0.0066)$ & $2.5747^{* * *}(0.0066)$ & $2.5821^{* * *}(0.0068)$ & $2.5978^{* * *}(0.0066)$ \\
\hline Main(tradefree) & $0.0017^{* * *}(0.0007)$ & $0.0017^{* * *}(0.0006)$ & $0.0017^{* *}(0.0007)$ & $0.0012^{*}(0.0007)$ & $0.0012^{* * *}(0.0002)$ \\
\hline Main(invfree) & $0.0010(0.0008)$ & $0.0009 *(0.0006)$ & $0.0013^{* *}(0.0005)$ & $0.0013^{* * *}(0.0005)$ & $0.0008^{* * *}(0.0001)$ \\
\hline Maim(finfree) & $0.0006^{* * *}(0.0002)$ & $0.0009^{* * *}(0.0003)$ & $0.0012^{* *}(0.0005)$ & $0.0010^{*}(0.0006)$ & $0.0005^{* * *}(0.0001)$ \\
\hline Diff(popd) & $0.0000^{* * *}(0.0000)$ & $0.0000^{* * *}(0.0000)$ & $0.0000^{* * *}(0.0000)$ & $0.0000^{* * *}(0.0000)$ & $0.0000^{* * *}(0.0000)$ \\
\hline Diff(gdpd) & $0.0007^{* * *}(0.0001)$ & $0.0007^{* * *}(0.00$ & $0.0007^{* * *}(0.0000)$ & $0.0007^{* * *}(0.0001)$ & $0.0007^{* * *}(0.0001)$ \\
\hline Diff(entry_cost) & $-0.0006(0.0005)$ & $-0.0007(0.0005)$ & $-0.0005(0.0005)$ & $-0.0006(0.0005)$ & $-0.0006(0.0005)$ \\
\hline Homo(gdphigh) & $0.0955^{* * *}(0.0056)$ & $0.1043^{* * *}(0.0054)$ & $0.0988^{* * *}(0.0055)$ & $0.0982^{* * *}(0.0056)$ & $0.0814^{* * *}(0.0056)$ \\
\hline $\operatorname{Homo}(\mathrm{p}$ & $0.0612^{* * *}(0.0053)$ & $0.0827^{* * *}(0.0053)$ & $0.0685^{* * *}(0.0052)$ & $0.0621^{* * *}(0.0054)$ & $0.0675^{* * *}(0.0053)$ \\
\hline Send(gdphigh) & $1.1989^{* * *}(0.0059)$ & $1.1825^{* * *}(0.0059)$ & $1.2264^{* * *}(0.0060)$ & $1.1906^{* * *}(0.0061)$ & $1.2123^{* * *}(0.0062)$ \\
\hline & $0.0787^{* * *}(0.0060)$ & $0.1060^{* * *}(0.0058)$ & $0.0480^{* * *}(0.0058)$ & $0.0444^{* * *}(0.0062)$ & $0.0583^{* * *}(0.0060)$ \\
\hline $\operatorname{Recv}$ & $0.1784^{* * *}(0.0062)$ & $0.1583^{* * *}(0.0061)$ & $0.1876^{* * *}(0.0061)$ & $0.1658^{* * *}(0.0062)$ & $0.2055^{* * *}(0.0060)$ \\
\hline Recv(pophigh) & $0.3159^{* * *}(0.0060)$ & $0.3305^{* * *}(0.0060)$ & $0.3197^{* * *}(0.0058)$ & $0.3141^{* * *}(0.0059)$ & $0.2862^{* * *}(0.0059)$ \\
\hline Netc(comlang_off) & $0.7088^{* * *}(0.0100)$ & & & & \\
\hline Netc(comlang_ethno) & & $0.6073^{* * *}(0.0082)$ & & & \\
\hline Netc(comleg) & & & $0.2176^{* * *}(0.0043)$ & & \\
\hline Netc(comrelig) & & & & $0.2041^{* * *}(0.0072)$ & \\
\hline Netc(sibling_ever) & & & & & $0.2824^{* * *}(0.0052)$ \\
\hline Num. obs. & 10620 & 10620 & 10620 & 10620 & 10620 \\
\hline
\end{tabular}

Note. ${ }^{* * *} p<0.01 ;{ }^{* *} p<0.05 ;{ }^{*} p<0.1$; the values in parentheses are standard errors.

Firstly, from the perspective of endogenous network structure variables, the estimated parameters of variable named edges in $\mathrm{M}(7)-\mathrm{M}(11)$ are all significantly negative. The estimation coefficients of variable named mutual in $\mathrm{M}(7)-\mathrm{M}(11)$ are all significantly positive, which indicates that the import trade between the BRI countries during 2001-2019 is mutual.

Secondly, from the perspective of exogenous network covariates, the estimated results of parameters of Netc(lang_off), Netc(lang_ethno), Netc(comleg), Netc(comleg), and Netc(sibling_ever) in $\mathrm{M}(7)-\mathrm{M}(11)$ are significantly positive, which shows that a common official language, a commonly spoken language, a common legal origin, common religious beliefs, and ever sibling relationship will help the 61BRI countries establish closer trade ties during 2001-2019.

Finally, we analyze the effects of individual attribute covariates.

(I) In terms of the main effect, the estimated coefficients of Main(tradefree) and Main(finfree) in $\mathrm{M}(7)-\mathrm{M}(11)$ are significantly positive, respectively, which shows that trade liberalization and financial liberalization have a significant role in promoting the formation of import trade networks of sample countries. The estimated coefficients of Main(invfree) in $M(7)-M(11)$ are positive, and the estimated coefficients of Main(invfree) in $M(8)-M(11)$ pass the $t$-test, which indicates that investment liberalization is conducive to the evolution of import trade network during 2001-2019. The results here show that the influence of investment liberalization on trade networks is different in the short run and long run, while investment liberalization in the long run is more conducive to form a close international trade relationship network.
(II) In the absolute difference effect, the estimated coefficients of Diff(gdp) and Diff(pop) in $M(7)-M(11)$ are significantly positive, which indicates that the differences in GDP and population size are conducive to the establishment of bilateral import trade relations of the BRI countries during 2001-2019. The estimated coefficient of Diff(entry_cost) is insignificantly negative, which cannot confirm that the difference of entry cost of enterprises become an obstacle to import trade across the BRI countries.

(III) In the aspect of homophily effect, the estimated coefficients of Homp(gdphigh) and Homp(pophigh) in $\mathrm{M}(7)-\mathrm{M}(11)$ are significantly positive, which indicates that among BRI countries in 2019, the import propensity among large GDP countries is large, as well as the import propensity of lager population countries.

(IV) In the aspect of sender effect, Send(gdphigh) and Send(pophigh) in $M(7)-M(11)$ are both significantly positive, which indicates that big GDP countries and large population countries are more popular in import trade during 2001-2019.

(V) In terms of receiver effect, Recv(gdplow) and Recv(poplow) in $M(7)-M(11)$ are both significantly negative in $M(7)-M(12)$, which indicates that the countries with small GDP and small population are not active enough in import trade and have fewer in-links during 2001-2019.

The overall results derived from temporal ERGM support the outcome obtained from cross-sectional ERGM in 2019 except for the influence of investment liberalization on import trade networks. 

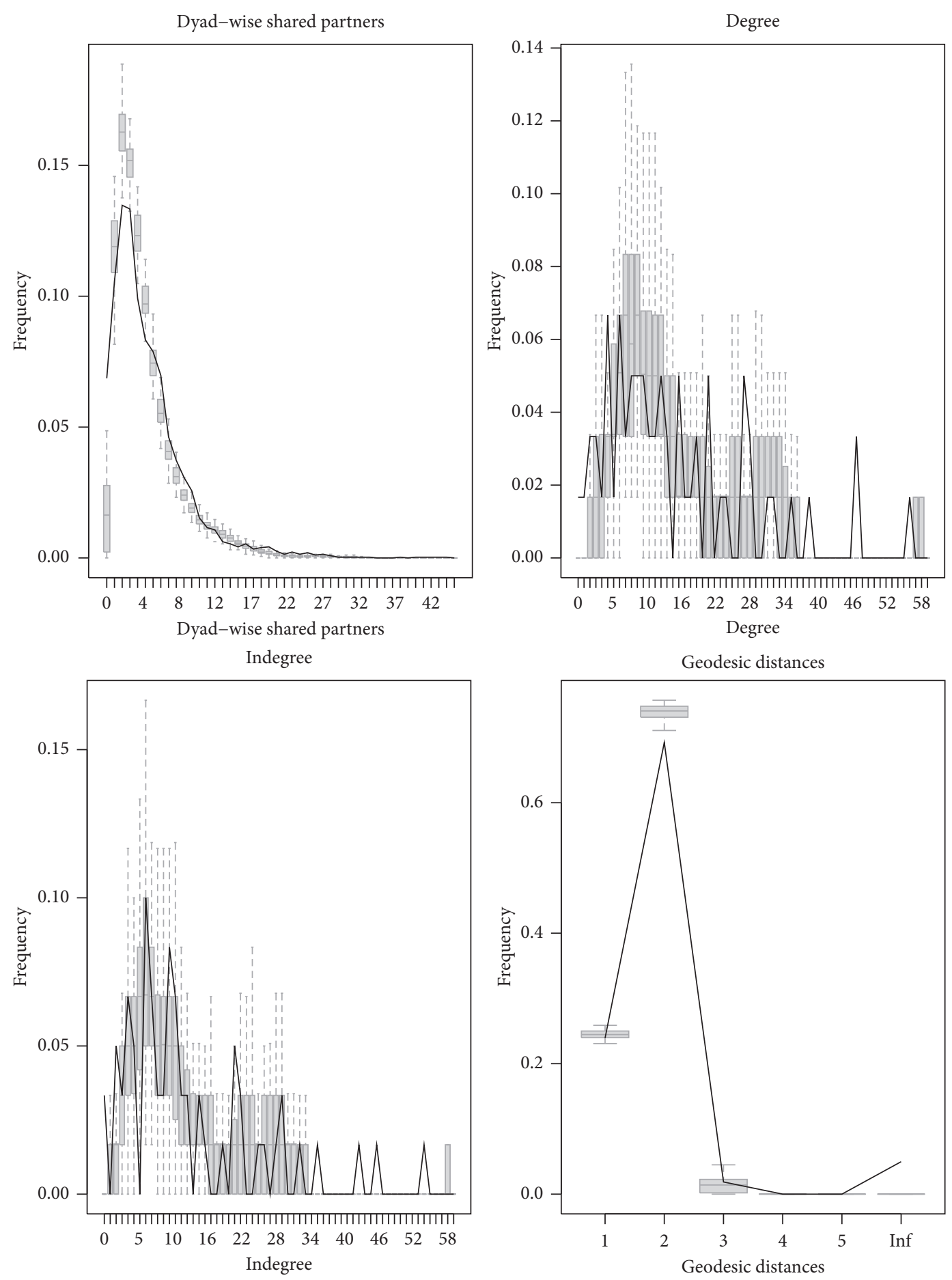

FIgURE 3: The fitting results of GOF in M(7).

4.3.2. The Estimated Results of the Temporal ERGM by Maximum Pseudo-Likelihood Estimation with a Bootstrapped Confidence Interval. For robustness, we have reestimated model (7) with the maximum pseudo-likelihood estimation with bootstrapped confidence interval (PLEBCI) instead of MCMC MLE. The results are presented in Table 5. It can be seen from Table 5 that in $M(12)-M(16)$, the estimated parameters of the endogenous network structure variable named the edges are negative, and the estimated coefficients of mutual are also significantly positive, which is consistent with the results in Table 4 . The estimated parameters of Netc(lang_off), Netc(lang_ethno), Netc(comleg), Netc(comleg), and Netc(sibling_ever) in M(12)-M(16) are all positive, which is consistent with the conclusion in Table 4. The difference is that some estimated parameters are not significant enough. In addition, the estimated parameter 
TABLE 5: The estimated results of the temporal ERGM by PLEBCI.

\begin{tabular}{|c|c|c|c|c|c|}
\hline & $\mathrm{M}(12)$ & $\mathrm{M}(13)$ & $\mathrm{M}(14)$ & $\mathrm{M}(15)$ & $\mathrm{M}(16)$ \\
\hline Edges & $\begin{array}{c}-3.4084^{*}[-11.1094 \\
-2.4679]\end{array}$ & $\begin{array}{c}-3.4368^{*}[-11.1202 \\
-2.5527]\end{array}$ & $\begin{array}{c}-3.4330^{*}[-11.3280 \\
-2.7876]\end{array}$ & $\begin{array}{c}-3.3410^{*}[-5.6840 \\
-2.4420]\end{array}$ & $\begin{array}{c}-3.4172 *[-11.1122 \\
-2.6241]\end{array}$ \\
\hline Mutual & $\begin{array}{c}2.5559^{*}[2.0462 ; \\
2.7470]\end{array}$ & $\begin{array}{c}2.5543^{*}[2.1505 \\
2.7389]\end{array}$ & $\begin{array}{c}2.5798^{*}[2.1594 \\
2.7512]\end{array}$ & $\begin{array}{c}2.5889^{*}[2.2417 \\
2.8065]\end{array}$ & $\begin{array}{c}2.5756^{*}[2.0628 \\
2.7944]\end{array}$ \\
\hline Main(tradefree) & $\begin{array}{c}0.0014[-0.0021 \\
0.0525]\end{array}$ & $\begin{array}{c}0.0015[-0.0017 \\
0.0526]\end{array}$ & $\begin{array}{c}0.0009[-0.0013 \\
0.0530]\end{array}$ & $\begin{array}{c}0.0009[-0.0024 \\
0.0142]\end{array}$ & $\begin{array}{c}0.0012[-0.0012 \\
0.0526]\end{array}$ \\
\hline Main(invfree) & $\begin{array}{c}0.0014[-0.0059 \\
0.0085]\end{array}$ & $\begin{array}{c}0.0012[-0.0051 \\
0.0085]\end{array}$ & $\begin{array}{c}0.0015[-0.0050 \\
0.0046]\end{array}$ & $\begin{array}{c}0.0012[-0.0040 \\
0.0079]\end{array}$ & $\begin{array}{c}0.0012[-0.0090 \\
0.0081]\end{array}$ \\
\hline Maim(finfree) & $\begin{array}{c}0.0006[-0.0063 \\
0.0079]\end{array}$ & $\begin{array}{c}0.0008[-0.0062 \\
0.0070]\end{array}$ & $\begin{array}{c}0.0009[-0.0027 \\
0.0080]\end{array}$ & $\begin{array}{l}0.0011[-0.0053 \\
0.0073]\end{array}$ & $\begin{array}{c}0.0008[-0.0058 \\
0.0095]\end{array}$ \\
\hline Diff(popd) & $\begin{array}{c}0.0000[-0.0022 \\
0.0008]\end{array}$ & $\begin{array}{c}0.0000[-0.0011 \\
0.0008]\end{array}$ & $\begin{array}{c}0.0000[-0.0020 \\
0.0001]\end{array}$ & $\begin{array}{c}0.0000[-0.0003 \\
0.0006]\end{array}$ & $\begin{array}{c}0.0000[-0.0030 \\
0.0007]\end{array}$ \\
\hline Diff(gdpd) & $\begin{array}{c}0.0007^{*}[0.0000 \\
0.0020]\end{array}$ & $\begin{array}{c}0.0007^{*}[0.0001 \\
0.0014]\end{array}$ & $\begin{array}{c}0.0007^{*}[0.0004 \\
0.0019]\end{array}$ & $\begin{array}{c}0.0007^{*}[0.0002 \\
0.0009]\end{array}$ & $\begin{array}{c}0.0007^{*}[0.0001 \\
0.0025]\end{array}$ \\
\hline Diff(entry_cost) & $\begin{array}{c}-0.0008[-0.0025 \\
0.0017]\end{array}$ & $\begin{array}{c}-0.0008[-0.0024 \\
0.0016]\end{array}$ & $\begin{array}{c}-0.0007[-0.0022 \\
0.0019]\end{array}$ & $\begin{array}{c}-0.0007[-0.0021 \\
0.0014]\end{array}$ & $\begin{array}{c}-0.0006[-0.0020 \\
0.0015]\end{array}$ \\
\hline Homo(gdphigh) & $\begin{array}{c}0.1046[-0.1006 \\
0.3162]\end{array}$ & $\begin{array}{c}0.1104[-0.0902 \\
0.2551]\end{array}$ & $\begin{array}{c}0.1077^{*}[0.0191 \\
0.3462]\end{array}$ & $\begin{array}{c}0.1073[-0.0987 \\
0.2014]\end{array}$ & $\begin{array}{c}0.1019[-0.1033 \\
0.3291]\end{array}$ \\
\hline Homo(pophigh) & $\begin{array}{c}0.0914^{*}[0.0244 \\
0.2856]\end{array}$ & $\begin{array}{c}0.0842^{*}[0.0170 \\
0.2291]\end{array}$ & $\begin{array}{c}0.0883^{*}[0.0234 \\
0.2703]\end{array}$ & $\begin{array}{c}0.0867^{*}[0.0238 \\
0.2015]\end{array}$ & $\begin{array}{c}0.0816^{*}[0.0157 \\
0.2760]\end{array}$ \\
\hline Send(gdphigh) & $\begin{array}{c}1.2163^{*}[0.3225 \\
2.3011]\end{array}$ & $\begin{array}{c}1.2021^{*}[0.3197 \\
2.0020]\end{array}$ & $\begin{array}{c}1.2242^{*}[0.6129 \\
2.3520]\end{array}$ & $\begin{array}{c}1.2169^{*}[0.2728 \\
1.8937]\end{array}$ & $\begin{array}{c}1.2377^{*}[0.3085 \\
2.4571]\end{array}$ \\
\hline Send(pophigh) & $\begin{array}{c}0.0764[-0.0967 \\
0.6106]\end{array}$ & $\begin{array}{c}0.0904[-0.0954 \\
0.6104]\end{array}$ & $\begin{array}{c}0.0660[-0.0985 \\
0.6242]\end{array}$ & $\begin{array}{c}0.0566[-0.1140 \\
0.2902]\end{array}$ & $\begin{array}{c}0.0728[-0.0728 \\
0.6182]\end{array}$ \\
\hline $\operatorname{Recv}($ gdphigh) & $\begin{array}{c}0.1842[-0.0054 \\
0.5725]\end{array}$ & $\begin{array}{c}0.1708[-0.0045 \\
0.5042]\end{array}$ & $\begin{array}{c}0.1875^{*}[0.0312 \\
0.5917]\end{array}$ & $\begin{array}{c}0.1803[-0.0580 \\
0.4700]\end{array}$ & $\begin{array}{c}0.2075[-0.0147 \\
0.7366]\end{array}$ \\
\hline Recv(pophigh) & $\begin{array}{c}0.3214^{*}[0.3058 \\
0.5245]\end{array}$ & $\begin{array}{c}0.3326^{*}[0.3014 \\
0.5245]\end{array}$ & $\begin{array}{c}0.3085^{*}[0.2324 \\
0.5413]\end{array}$ & $\begin{array}{c}0.2994^{*}[0.2611 \\
0.3592]\end{array}$ & $\begin{array}{c}0.3137^{*}[0.2354 \\
0.5332]\end{array}$ \\
\hline Netc(comlang_off) & $\begin{array}{c}0.7087[-0.3521 \\
1.6002]\end{array}$ & & & & \\
\hline Netc(comlang_ethno) & & $\begin{array}{c}0.6138[-0.1365 \\
1.0453]\end{array}$ & & & \\
\hline Netc(comleg) & & & $\begin{array}{c}0.2301^{*}[0.1498 \\
0.5666]\end{array}$ & & \\
\hline Netc(comrelig) & & & & $\begin{array}{c}0.2005[-0.1257 \\
0.6396]\end{array}$ & \\
\hline Netc(sibling_ever) & & & & & $\begin{array}{c}0.3330[-0.1117 \\
1.0982]\end{array}$ \\
\hline Obs. & 10620 & 10620 & 10620 & 10620 & 10620 \\
\hline
\end{tabular}

Note. ${ }^{* * *} p<0.01 ;{ }^{* *} p<0.05 ;{ }^{*} p<0.1$.

properties (positive and negative) of node attribute are basically consistent with the results in Table 4, which shows that the main effect, absolute difference effect, homophily effect, sender effect, and receiver effect of the node attributes are basically consistent with the results in Table 4 .

\section{Conclusions and Policy Implications}

Humanistic factors have been playing increasingly significant roles in international trade, and network analysis is one of the profound methods to empirically integrate complex relationships. In doing so, this paper has become the first of its kind which analyzes the structural characteristics of import trade network across the 61 BRI countries and subsequently adopts the cross-sectional ERGM and temporal ERGM method to test the role of different humanistic factors such as language, religious belief, the origin of law, and other factors in the evolution of the import trade network from the static and dynamic perspectives. Primarily, three conclusions are drawn from this study.

First, the network scale of the import trade network has expanded, and the density of import trade networks of the BRI countries has gradually increased during 2001-2019. The "small-world" characteristics of import network are gradually revealed. During 2001-2019, the core countries of import trade network also decreased from four countries (Singapore, China, Malaysia, and Russia) in 2001 and 2005 to one country (China) in 2013 and 2019. Core-periphery characteristics of import trade networks of BRI countries are more significant. China has moved to a central position in the import trade network among BRI countries and become a hub node.

Second, the estimated results of the cross-sectional ERGM and temporal ERGM both verified the reciprocal effect affecting the evolution of BRI trade network. The empirical results also found that a common official language, 
a commonly spoken language relationship, a common legal origin, a common religious belief, and ever sibling relationship are conducive to the BRI countries establishing closer import trade ties.

Third, the individual attributes of the BRI countries, such as the level of trade liberalization and financial liberalization, the difference of GDP, and population, are all beneficial to the evolution of the import trade network. Relatively higher GDP countries and greater population countries are active in import trade networks. follows.

The policy implications of the above conclusions are as

Firstly, to promote closer economic and trade relations among the BRI countries, BRI countries should further strengthen cross-cultural exchanges and cooperation. Taking China for example, to promote cross-cultural exchanges and cooperation among BRI countries, China has actively carried out business cooperation with the countries, established Confucius Institutes in the BRI countries, and provided generous scholarships for foreign students, and so on. These tools enhance the ability of Chinese cultural exchange, which can translate into higher acceptance of BRI projects and create greater opportunities for transnational trade.

Secondly, the core countries should take more responsibility in promoting closer trade relationships among the BRI partners. China has moved to a central position in the import trade network among BRI countries and become a hub node. This means that the Chinese government should play a pivotal role in promoting economic and trade cooperation, deepen international trade relations, and improve the intensity of trade relationships across the BRI countries.

Thirdly, implementation of the BRI strategy helps eliminate trade barriers between high-economic and loweconomic countries. Meanwhile, it enhances the grade effect of import trade network among the BRI countries, leading to greater trade gaps among BRI countries. As the advocator and promoter of the BRI strategy, China needs to coordinate the trade competition among BRI countries, pay close attention to the countries that are overly dependent on imports to avoid the excessive trade deficit, and actively promote the establishment and maintenance of multilateral and multilevel trade partnership.

This study can be extended in several ways. The import trade network in this study mainly includes commodity trade networks, so whether the service trade network can reach the same conclusion needs further investigation. In addition, due to the variety of commodity trade and the immense difference of products in different countries [54], the heterogeneity characteristics of different types of commodity trade networks are significant [54]. Whether the influences of the humanistic relations on different types of commodity trade networks have heterogeneity needs to be further verified.

\section{Data Availability}

Import trade data of sample countries come from UN Comtrade_SITC dataset (https://www.trademap.org/Index. aspx\#). Common official or primary language data, a common language spoken by at least $9 \%$ of the population data, common religious belief data, common legal origin data, ever sibling relationship data, and entry cost data come from the CEPII Gravity Database (http://www.cepii.fr/ CEPII/en/welcome.asp). The basic data of GDP and population are all from the World Bank Database (https://data. worldbank.org.cn). The measurement data of trade liberalization, investment liberalization, and financial liberalization come from the database provided by the Global Heritage Fund (https://www.heritage.org/).

\section{Conflicts of Interest}

The authors declare that there are no conflicts of interest regarding the publication of this paper.

\section{Acknowledgments}

This work was financially sponsored by the Humanities and Social Sciences Research Youth Foundation Project of the Ministry of Education in China (nos. 16YJCZH124 and 17YJCZH218), Key Funding Projects of Humanities and Social Sciences of Universities in Zhejiang Province (no. 2016QN005), Soft Science Research Program of Department of Science and Technology in Zhejiang Province (no. 2022C35050), and Project of School of Science \& Technology, Ningbo University (no. YK202113).

\section{References}

[1] H. Xu and L. Cheng, "The study of the influence of common humanistic relations on international services trade-from the perspective of multi-networks," Physica A: Statistical Mechanics and its Applications, vol. 523, pp. 642-651, 2019.

[2] R. Guo, "How culture influences foreign trade: evidence from the U.S. and China," The Journal of Socio-Economics, vol. 33, no. 6, pp. 785-812, 2004

[3] G. J. M. Linders, A. Slangen, H. L. F de Groot, and S. Beugelsdijk, Cultural and Institutional Determinants of Bilateral Trade Flows, Tinbergen Institute Discussion Paper, Amsterdam, Netherlands, 2005.

[4] B. Tadesse and R. White, "Does cultural distance hinder trade in goods? a comparative study of nine OECD member nations," Open Economies Review, vol. 21, no. 2, pp. 237-261, 2010.

[5] B. Tadesse, R. White, and H. Zhongwen, "Does China's trade defy cultural barriers?" International Review of Applied Economics, vol. 31, no. 3, pp. 398-428, 2017.

[6] A. Liu, C. Lu, and Z. Wang, "The roles of cultural and institutional distance on international trade: evidence from China's trade with the Belt and Road countries," China Economic Review, vol. 61, 2020.

[7] A. V. Deardorff, "Local comparative advantage: trade costs and the pattern of trade," International Journal of Economic Theory, vol. 10, no. 1, pp. 9-35, 2014.

[8] M. Obstfeld and K. Rogoff, "The six major puzzles in international macroeconomics: is there a common cause?" NBER Macroeconomics Annual, vol. 15, no. 1, pp. 339-390, 2000.

[9] D. Ma, C. Lei, F. Ullah, R. Ullah, and Q. B. Baloch, "China's one Belt and one Road initiative and outward Chinese foreign direct investment in europe," Sustainability, vol. 11, no. 24, pp. 1-13, 2019. 
[10] F. Chen, G. Jiang, and G. M. Kitila, "Trade openness and CO2 emissions: the heterogeneous and mediating effects for the belt and road Countries," Sustainability, vol. 13, no. 4, pp. 1-16, 2021.

[11] K. Bhattacharya, G. Mukherjee, J. Saramäki, K. Kaski, and S. S. Manna, "The international trade network: weighted network analysis and modelling," Journal of Statistical Mechanics: Theory and Experiment, vol. 2008, no. 2, Article ID P02002, 2008.

[12] G. Fagiolo, J. Reyes, and S. Schiavo, "On the topological properties of the world trade web: a weighted network analysis," Physica A: Statistical Mechanics and Its Applications, vol. 387, no. 15, pp. 3868-3873, 2008.

[13] G. Fagiolo, J. Reyes, and S. Schiavo, "World-Trade Web: topological properties, dynamics, and evolution," Physical review. E, Statistical, nonlinear, and soft matter physics, vol. 79, no. 3, Article ID 36115, 2009.

[14] G. Fagiolo, "The international-trade network: gravity equations and topological properties," Journal of Economic Interaction and Coordination, vol. 5, no. 1, pp. 1-25, 2010.

[15] M. Dueñas and G. Fagiolo, "Modeling the international-trade network: a gravity approac," Journal of Economic Interaction and Coordination, vol. 8, no. 1, pp. 155-178, 2013.

[16] Y. Fan, S. Ren, H. Cai, and X. Cui, "The state's role and position in international trade: a complex network perspective," Economic Modelling, vol. 39, no. 4, pp. 71-81, 2014.

[17] M. Zhou, G. Wu, and H. Xu, "Structure and formation of top networks in international trade," Social Networks, vol. 44, pp. 9-21, 2016.

[18] X. Dong, F. An, Z. Dong et al., "Optimization of the international nickel ore trade network," Resources Policy, vol. 70, Article ID 101978, 2021.

[19] S. Chen and Q. Qiang, "The trade network structure of the "One Belt and One Road" and its environmental effects," Sustainability, vol. 12, no. 9, pp. 1-21, 2020.

[20] S. M. Goodreau, "Advances in exponential random graph ( $\left.\mathrm{p}^{*}\right)$ models applied to a large social network," Social Networks, vol. 29, no. 2, pp. 231-248, 2007.

[21] G. Robins, P. Pattison, Y. Kalish, and D. Lusher, "An introduction to exponential random graph $\left(\mathrm{p}^{*}\right)$ models for social networks," Social Networks, vol. 29, no. 2, pp. 173-191, 2007.

[22] D. Lusher, J. Koskinen, and G. L. Robins, Exponential Random Graph Models for Social Network: Theory, Methods, and Application, Cambridge University Press, Cambridge, UK, 2013.

[23] A. Dubnjakovic, "An evaluation of exponential random graph modeling and its use in library and information science studies," Library \& Information Science Research, vol. 38, no. 3, pp. 259-264, 2016.

[24] M. J. Silk and D. N. Fisher, "Understanding animal social structure: exponential random graph models in animal behaviour research," Animal Behaviour, vol. 132, no. 10, pp. 137-146, 2017.

[25] L. Feng, H. Xu, G. Wu, Y. Zhao, and J. Xu, "Exploring the structure and influence factors of trade competitive advantage network along the Belt and Road," Physica A: Statistical Mechanics and Its Applications, vol. 559, Article ID 125037, 2020.

[26] D. R. Hunter, M. S. Handcock, C. T. Butts, S. M. Goodreau, and M. Morris, "A package to fit, simulate and diagnose exponential-family models for networks," Journal of Statistical Software, vol. 24, no. 3, pp. 1-29, 2008.

[27] G. Wu, L. Feng, M. Peres, and J. Dan, "Do self-organization and relational embeddedness influence free trade agreements network formation? evidence from an exponential random graph model," Journal of International Trade \& Economic Development, vol. 29, no. 8, pp. 995-1017, 2020.

[28] P. Leifeld, S. J. Cranmer, and B. A. Desmarais, "Temporal exponential random graph models with btergm: estimation and bootstrap confidence intervals," Journal of Statistical Software, vol. 83, no. 6, pp. 1-3, 2018.

[29] S. Hanneke, W. Fu, and E. Xing, "Discrete temporal models of social networks," Electronic Journal of Statistics, vol. 4, pp. 585-605, 2010.

[30] N. S. Luo, Globalization, International Trade and Cultural Interaction, China Economic Publishing House, Beijing, China, 2006.

[31] G. J. Felbermayr and F. Toubal, "Cultural proximity and trade," European Economic Review, vol. 54, no. 2, pp. 279-293, 2010.

[32] Y. Takara, "Do cultural differences affect the trade of cultural goods? a study in trade of music," Journal of Cultural Economics, vol. 42, no. 3, pp. 393-417, 2018.

[33] H. O. Chang, W. T. Selmier, and D. Lien, "International trade, foreign direct investment, and transaction costs in languages," The Journal of Socio-Economics, vol. 40, no. 6, pp. 732-735, 2011.

[34] J. Melitz, "Language and foreign trade," European Economic Review, vol. 52, no. 4, pp. 667-699, 2008.

[35] J. Melitz and F. Toubal, "Native language, spoken language, translation and trade," Journal of International Economics, vol. 93, no. 2, pp. 351-363, 2014.

[36] J. Fidrmuc and J. Fidrmuc, "Foreign languages and trade: evidence from a natural experiment," Empirical Economics, vol. 50, no. 1, pp. 31-49, 2016.

[37] J. J. Lewer and H. Van den Berg, "Religion and international trade: does the sharing of a religious culture facilitate the formation of trade networks?" The American Journal of Economics and Sociology, vol. 66, no. 4, pp. 765-794, 2007.

[38] M. B. M. Lankhuizen and H. L. F. de Groot, "Cultural distance and international trade: a non-linear relationship," Letters in Spatial and Resource Sciences, vol. 9, no. 1, pp. 19-25, 2016.

[39] Z. Chong, C. Qin, and S. Pan, "The evolution of the Belt and Road trade network and its determinant factors," Emerging Markets Finance and Trade, vol. 55, no. 14, pp. 3166-3177, 2018.

[40] D. Dong, X. Gao, X. Sun, and X. Liu, "Factors affecting the formation of copper international trade community: based on resource dependence and network theory," Resources Policy, vol. 57, pp. 167-185, 2018.

[41] L. C. Freeman, "Centrality in social networks conceptual clarification," Social Networks, vol. 1, no. 3, pp. 215-239, 1978.

[42] C. S. Fischer and Y. Shavit, "National differences in network density: Israel and the United States," Social Networks, vol. 17, no. 2, pp. 129-145, 1995.

[43] D. J. Watts and S. H. Strogatz, "Collective dynamics of "smallworld” networks,” Nature, vol. 393, no. 6684, pp. 440-442, 1998.

[44] J. Liu, Z. Chong, and S. Lu, “The evolution and determinants of interorganizational coinvention networks in new energy vehicles: evidence from Shenzhen, China," Complexity, vol. 2021, Article ID 6665945, 12 pages, 2021.

[45] G. Robins, T. Snijders, P. Wang, M. Handcock, and P. Pattison, "Recent developments in exponential random graph $(\mathrm{p} *)$ models for social networks," Social Networks, vol. 29, no. 2, pp. 192-215, 2007.

[46] T. A. B. Snijders, P. E. Pattison, G. L. Robins, and M. S. Handcock, "New specifications for exponential random 
graph models," Sociological Methodology, vol. 36, no. 1, pp. 99-153, 2006.

[47] M. S. Handcock, D. R. Hunter, C. T. Butts, S. M. Goodreau, and M. Morris, "Statnet: software tools for the representation, visualization, analysis and simulation of network data," Journal of Statistical Software, vol. 24, no. 1, pp. 1548-7660, 2008.

[48] M. Morris, M. S. Handcock, and D. R. Hunter, "Specification of exponential-family random graph models: terms and computational aspects," Journal of Statistical Software, vol. 24, no. 4, pp. 1-23, 2008.

[49] P. N. Krivitsky, "Fit, simulate and diagnose exponentialfamily models for networks with count edges( $\mathrm{r}$ package ergm.count version 3.10.4)," 2019, https://cran.r-project.org/.

[50] P. J. Carrington, J. Scott, and S. Wasserman, Models and Methods in Social Network Analysis, Cambridge University Press, New York, NY, USA, 2005.

[51] M. Conte, P. Cotterlaz, and T. Mayer, "The CEPII gravity database," 2021, http://www.cepii.fr/DATA_DOWNLOAD\% 20/gravity/\%20doc/.

[52] A. L. Barabasi and R. Albert, "Emergence of scaling in random networks," Science, vol. 286, no. 5439, pp. 509-512, 1999.

[53] Z. Song, S. Che, and Y. Yang, "The trade network of the belt and road Initiative and its topological relationship to the global trade network," Journal of Geographical Sciences, vol. 28, no. 9, pp. 1249-1262, 2018.

[54] H. Xu, T. Sun, and L. H. Cheng, "Trade patterns and influence factors of high-end manufacturing on one belt and one road: a study based on the exponential random graph models," Financial and Trade Economics, vol. 12, pp. 74-88, 2015. 